\title{
Optimizing outcomes after coronary artery bypass grafting: The argument for dual antiplatelet therapy
}

\author{
Michael E. Halkos, MD, MSc
}

\author{
From the Division of Cardiothoracic Surgery, Emory University School of Medicine, Atlanta, Ga. \\ Disclosures: Author has nothing to disclose with regard to commercial support. \\ Received for publication Sept 4, 2015; accepted for publication Sept 8, 2015; available ahead of print Oct 13, 2015. \\ Address for reprints: Michael E. Halkos, MD, MSc, Division of Cardiothoracic Surgery, Emory University School \\ of Medicine and Emory University Hospital Midtown, 550 Peachtree St, NE, Medical Office Tower 6th Floor, \\ Atlanta, GA 30308 (E-mail: mhalkos@emory.edu). \\ J Thorac Cardiovasc Surg 2015;150:1555-6 \\ $0022-5223 / \$ 36.00$ \\ Copyright (C) 2015 by The American Association for Thoracic Surgery \\ http://dx.doi.org/10.1016/j.jtcvs.2015.09.046
}

In this month's issue of the Journal, Yanagawa and colleagues ${ }^{1}$ highlight an important topic that is frequently overlooked by surgeons. Numerous trials have shown improved cardiovascular outcomes for patients treated with dual antiplatelet therapy (DAPT) after presenting with acute coronary syndrome (ACS). In this survey of 75 Canadian cardiac surgeons, only $45 \%$ reinitiate DAPT after a routine coronary artery bypass grafting (CABG) in patients with ACS. Only 60\% were aware of the current guidelines about DAPT in patients presenting with an ACS, and only $64 \%$ of respondents believed that the ACS patients treated with CABG can benefit from DAPT.

The guidelines are hardly compelling. The American Heart Association/American College of Cardiology guidelines recommend that patients with prior $\mathrm{CABG}$ and non-ST elevation ACS should receive antiplatelet therapy according to guideline-directed medical therapy but do not provide specifics. ${ }^{2}$ The European Society of Cardiology recommends restarting $\mathrm{P}_{2} \mathrm{Y}_{12}$ inhibitors after CABG when safe. ${ }^{3}$ Neither of these recommendations comments on the timing or duration of DAPT. The Canadian Cardiovascular Society offers the strongest recommendation that "DAPT should be restarted after surgery and continued for 12 months to decrease the risk of recurrent ACS." 4 Although this survey by Yanagawa and colleagues ${ }^{1}$ was limited to Canadian surgeons, the results very likely apply to those of us south of the border and beyond.

The reluctance of surgeons to reinitiate DAPT is understandable for 2 key reasons: concerns for bleeding and lack of data that apply specifically to patients undergoing CABG, especially level-A or even level-B evidence.

Most of the clinical trial data comparing DAPT to aspirin alone for patients presenting with ACS included a heterogeneous group of patients treated with medical; percutaneous; or, less often, surgical therapy. This includes well-known trials such as Clopidogrel in unstable angina to prevent recurrent events trial (CURE), ${ }^{5}$ PLATelet inhibition and patient Outcomes trial (PLATO), ${ }^{6}$ and Evaluation of prasugrel

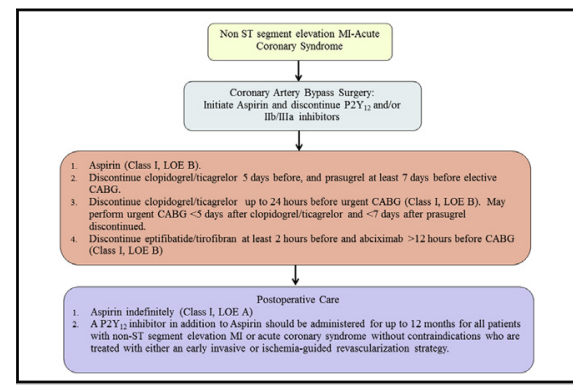

Algorithm for management of patients with definite or likely non-ST-segment elevation acute coronary syndrome (NSTE-ACS).

Central Message

Dual antiplatelet therapy may improve outcomes after $\mathrm{CABG}$, provided that the risk of bleeding does not exceed the risk of ischemia.

See Article page 1548.

compared with clopidogrel in patients with acute coronary syndromes: design and rationale for the TRial to assess Improvement in Therapeutic Outcomes by optimizing platelet InhibitioN with prasugrel Thrombolysis In Myocardial Infarction (TRITON-TIMI). ${ }^{7}$ Post-hoc analyses in CABG subgroups suggested a benefit of DAPT, but several studies have shown no benefit.

One of the well-known benefits of CABG is a vesseltreatment strategy in comparison to a lesion treatment strategy with percutaneous intervention. Because bypass grafts typically bypass the proximal one-half to two-thirds of the coronary artery, this alone provides protection against recurrent ischemic events, provided that the graft remains patent and that all major vessels are revascularized. This may at least partly explain the multifarious results from the currently available trials. Therefore, the real question is whether or not DAPT affects graft patency, especially vein grafts. Unfortunately, there are as many studies refuting this argument as there are supporting it.

Bleeding, whether early during the postoperative period or later, is a primary concern for surgeons. Bleeding complications may not only manifest as frank hemorrhage, but also as more subtle problems like pleural or pericardial effusions. In both CURE ${ }^{5}$ and TRITON-TIMI, ${ }^{7}$ major bleeding was significantly higher in the DAPT groups compared with aspirin alone, although there was no difference noted with ticagrelor in the PLATO trial. ${ }^{6}$ 
Given the paucity of clinical trials evaluating DAPT for patients with ACS undergoing $\mathrm{CABG}$, what can we conclude? Undoubtedly there are patients undergoing CABG with poor distal targets, severe diffuse disease, incompletely revascularized territories, or other significant risk factors (including presentation with ACS) for recurrent ischemic coronary events that would likely benefit from prolonged DAPT therapy after CABG. In patients with uncomplicated pathology with a low risk of bleeding complications, there may also be a subtle yet significant benefit with DAPT. However, until definitive trial data become available, surgeon discretion will ultimately be the decisive factor. This needs to be based on the risks of postoperative bleeding complications versus the risk for recurrent ischemic events.

\section{References}

1. Yanagawa B, Ruel M, Bonneau C, Lee M, Chung J, Al Shouli S, et al. Dual antiplatelet therapy use by Canadian cardiac surgeons. J Thorac Cardiovasc Surg. 2015;150:1548-54.e1-3.
2. Amsterdam EA, Wenger NK, Brindis RG, Casey DE Jr, Ganiats TG, Holmes DR Jr, et al. 2014 AHA/ACC guideline for the management of patients with non -ST-elevation acute coronary syndromes: executive summary: a report of the American College of Cardiology/American Heart Association Task Force on Practice Guidelines. Circulation. 2014;130: 2354-94.

3. Hamm CW, Bassand JP, Agewall S, Bax J, Boersma E, Bueno H, et al. ESC Guidelines for the management of acute coronary syndromes in patients presenting without persistent ST segment elevation: The Task Force for the management of acute coronary syndromes (ACS) in patients presenting without persistent STsegment elevation of the European Society of Cardiology (ESC). Eur Heart J. 2011;32:2999-3054.

4. Tanguay JF, Bell AD, Ackman ML, Bauer RD, Cartier R, Chan WS, et al. Focused 2012 update of the Canadian Cardiovascular Society guidelines for the use of antiplatelet therapy. Can J Cardiol. 2013;29:1334-45.

5. Yusuf S, Zhao F, Mehta SR, Chrolavicius S, Tognoni G, Fox KK. Effects of clopidogrel in addition to aspirin in patients with acute coronary syndromes without ST-segment elevation. N Engl J Med. 2001;345:494-502.

6. Wallentin L, Becker RC, Budaj A, Cannon CP, Emanuelsson H, Held HC, et al. Ticagrelor versus clopidogrel in patients with acute coronary syndromes. $N$ Engl J Med. 2009;361:1045-57.

7. Wiviott SD, Braunwald E, McCabe CH, Montalescot G, Ruzyllo W, Gottlieb S, et al. Prasugrel versus clopidogrel in patients with acute coronary syndromes. $N$ Engl J Med. 2007;357:2001-15. 